\title{
Self-measurement of IOP by patients with normal tension glaucoma before and after SLT
}

\author{
Alexandra Young $\mathbb{1}^{1,2} \cdot$ Frederick R. Burgess ${ }^{1,3} \cdot$ Andrew Tatham $\mathbb{1}^{1,2}$ \\ Received: 19 September 2020 / Revised: 5 October 2020 / Accepted: 11 November 2020 / Published online: 13 May 2021 \\ (c) The Royal College of Ophthalmologists 2020
}

\section{To the Editor:}

We commend the efforts of Choudhari et al. to improve teleophthalmology in glaucoma [1]. It is not just rural, underserved areas that can benefit from such progress. Given the COVID-19 pandemic and the mounting pressures on NHS ophthalmology services, novel ways to reduce in-person hospital attendances are needed in all settings.

At present the treatment for all types of glaucoma aims to lower intraocular pressure (IOP). IOP is typically measured using a Goldmann Applanation Tonometer (GAT) in the clinic setting. The iCare tonometer (iCare, Finland) is a rebound tonometer that has similar accuracy to GAT and can be used by the patient at home [2]. Pronin et al found that $73 \%$ of patients could successfully perform selftonometry with an iCare HOME Tonometer [3].

We present results from a prospective, clinic-based pilot study examining self-measurement of intraocular pressure by patients after selective laser trabeculoplasty (SLT).

Two patients with normal tension glaucoma (NTG) underwent SLT treatment in one eye only. They measured their IOP in both eyes with the iCare HOME tonometer at 2 a.m., 4 a.m., 7 a.m., 9 a.m., 11 a.m., 1 p.m., 3 p.m., 5 p.m., 7 p.m. and 11 p.m. for 3 days before SLT and 3 days after SLT. They also measured their IOP 4 weeks after SLT at the same times for 3 days, giving a total of 198 IOP measurements.

The patients were taught how to use the iCare HOME in a 30 minute teaching session. Patients were asked to measure their own IOP at the end of the session, which was then compared to the measurements taken by the clinician.
Success was defined as being within $4 \mathrm{mmHg}$ of the clinician's measurements.

In the treated eye of both patients, there was on average a $19.75 \%$ reduction in mean IOP 4 weeks after SLT $(p \leq 0.001$, CI 95\%). Results can be seen in Table 1 .

Our results are similar to data from a 2014 study, which found a $17 \%$ reduction in IOP after SLT for NTG patients [4]. Had the peak IOP been recorded at a clinic visit following SLT, rather than the average IOP at home, the SLT would have been deemed ineffective in both our patients. Peak IOP occurred between 7 a.m. and 1 p.m. in both patients at all study points, meaning clinic IOP could well have captured the peak IOP and led to the clinician prescribing topical ocular anti-hypertensives.

Both patients in our study were successful in measuring their own IOP after a 4 week break. Pronin et al mentioned a limitation of their study was that they could not comment on whether ability to use the device is maintained over time [3]. In our pilot, ability was maintained without a further teaching session. This indicates that the iCare HOME is easy to use and the ability to use it is maintained over time.

The iCare HOME is a useful tool in home monitoring of IOP, thereby reducing the number of patient attendances to hospital for IOP monitoring, as well as giving a true indication of IOP after SLT and potentially avoiding unnecessary eye drops.

\section{Compliance with ethical standards}

Conflict of interest The authors declare that they have no conflict of interest.
Alexandra Young

alexandra.young@nhslothian.scot.nhs.uk

1 Princess Alexandra Eye Pavilion, NHS Lothian, Edinburgh, UK
2 Department of Ophthalmology, University of Edinburgh, Edinburgh, UK

3 School of Medicine, University of St Andrews, St Andrews, UK 
Table 1 iCare HOME results from both patients.

\begin{tabular}{|c|c|c|c|c|c|c|c|c|}
\hline & \multicolumn{4}{|l|}{ Patient 1} & \multicolumn{4}{|l|}{ Patient 2} \\
\hline & Recordings & $\begin{array}{l}\text { Mean } \\
\text { IOP }(\mathrm{mmHg})\end{array}$ & $\begin{array}{l}\text { Peak } \\
\text { IOP }(\mathrm{mmHg})\end{array}$ & $\mathrm{SD}(\mathrm{mmHg})$ & Recordings & $\begin{array}{l}\text { Mean } \\
\text { IOP }(\mathrm{mmHg})\end{array}$ & $\begin{array}{l}\text { Peak } \\
\text { IOP }(\mathrm{mmHg})\end{array}$ & $\mathrm{SD}(\mathrm{mmHg})$ \\
\hline Before SLT & 37 & 15.6 & 20 & 3.2 & 35 & 14.3 & 20 & 2.7 \\
\hline $\begin{array}{l}3 \text { days } \\
\text { after SLT }\end{array}$ & 23 & 9.3 & 13 & 1.8 & 26 & 9.2 & 12 & 1.5 \\
\hline $\begin{array}{l}4 \text { weeks } \\
\text { after SLT }\end{array}$ & 30 & 12.4 & 17 & 2.6 & 29 & 12.8 & 18 & 2.6 \\
\hline
\end{tabular}

Publisher's note Springer Nature remains neutral with regard to jurisdictional claims in published maps and institutional affiliations.

\section{References}

1. Choudhari NS, Chandran P, Rao HL, Jonnadula GB, Addepalli UK, Senthil S, et al. LVPEI Glaucoma Epidemiology and Molecular Genetic Study: teleophthalmology screening for angle-closure disease in an underserved region. Eye. 2020;34:1399-405.
2. Gao F, Liu X, Zhao Q, Pan Y. Comparison of the iCare rebound tonometer and the Goldmann applanation tonometer. Exp Ther Med. 2017;13:1912-6.

3. Pronin S, Brown L, Megaw R, Tatham AJ. Measurement of intraocular pressure by patients with glaucoma. JAMA Ophthalmol. 2017;135:1030-6.

4. Lee JW, Fu L, Chan JC, Lai JS. Twenty-four-hour intraocular pressure related changes following adjuvant selective laser trabeculoplasty for normal tension glaucoma. Medicine. 2014;93:e238. 